\title{
Preparation and Characterization of Polyoxetane Resins Having a Primary Amino Group at the Side Chain-End through Moderately Long Spacer Arms
}

\author{
Masatoshi Motoi, Satoshi Sekizawa, Keisuke Asakura, \\ and Shigeyoshi KANOH \\ Department of Chemistry and Engineering Chemistry, Faculty of Technology, \\ Kanazawa University, Kodatsuno, Kanazawa 920, Japan
}

(Received May 17, 1993)

\begin{abstract}
Uncross- and cross-linked polyoxetanes having a pendant hydrophilic primary amino group at the terminal of the $-\mathrm{CH}_{2} \mathrm{O}\left(\mathrm{CH}_{2}\right)_{n}$ spacers, where $n=4$ and 6 , were prepared. Their prepolymers were obtained by the $\mathrm{BF}_{3}$-initiated cationic ring-opening polymerization of oxetanes having the corresponding pendant phthalimido group at the C-3 position of the oxetane ring. In this polymerization a bisoxetane or an oxetane having the hydrophobic pendant was used as a cross-linking agent or a comonomer modifying the degree of hydrophilicity. The pendant phthalimide of the prepolymers was reduced with hydrazine in ethanol at $40^{\circ} \mathrm{C}$ to give the pendant amine of the product polymers. The characterization of the phthalimide- and amine-containing polyoxetanes was also performed to know their structures and qualities. The analogous oxetane with the phthalimidomethyl pendant at the $\mathrm{C}-3$ position gave a tricyclic product via an intramolecular nucleophilic attack of the phthalimido oxygen atom on the methylene carbon atom of the oxetane ring.

KEY WORDS Cationic Ring-Opening Polymerization / Polyoxetanes / Pendant Amine / Pendant Phthalimide /
\end{abstract}

In a series of investigations of using polyethers as polymeric supports in organic synthesis, we synthesized polyethers carrying typical functional groups, such as halide, alcohol, phenol, amine, and carbonyl moieties, in the pendant side chain. The ordinary organic reactions of these functional groups are well-known, so various synthetic routes of functional polymers are expected to be found by chemical modification using the pendant functional groups as starting materials. Furthermore, we consider that polyether networks are promising as polymeric supports due to the desirable properties of ether linkages and that the existence of a spacer between the polymeric support and the functional group is also important in designing functional polymers. ${ }^{1,2}$ Polyethers with such functional groups, how- ever, are so far scarcely prepared, especially those having functional groups at the terminal of moderately long spacer arms, although methylene spacer-separated pendant functional groups were obtained by a substitution reaction of poly[3,3-bis(chloromethyl)oxetane] with several nucleophiles under considerable hard conditions. $^{3}$

Thus, since the primary anime is accepted as one of the key functional groups in the functional polymers synthesis, we have a great interest in the chemical reactivity and properties of the spacer-separated primary amine based on polyoxetanes. In our investigation, we found the cationic ring-opening polymerization of the oxetane rings of $N$-[6-(3-methyl-3oxetanyl)-5-oxahexyl]- and $\mathrm{N}$-[8-(3-methyl-3oxetanyl)-7-oxaoctyl]phthalimides (2a and $\mathbf{2 b}$ ) 


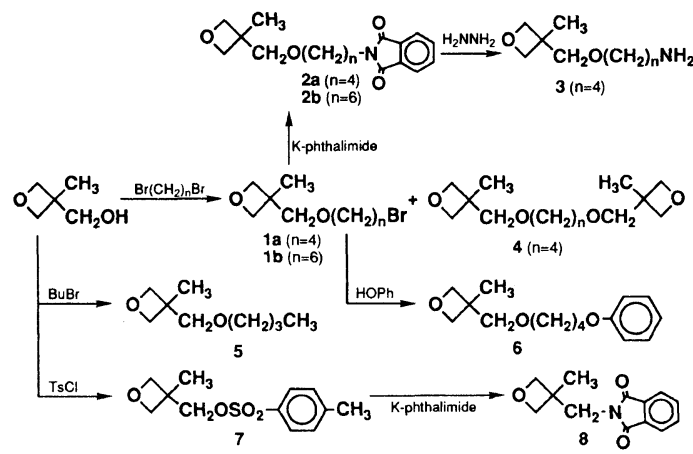

Scheme 1. Synthetic routes of oxetane monomers.

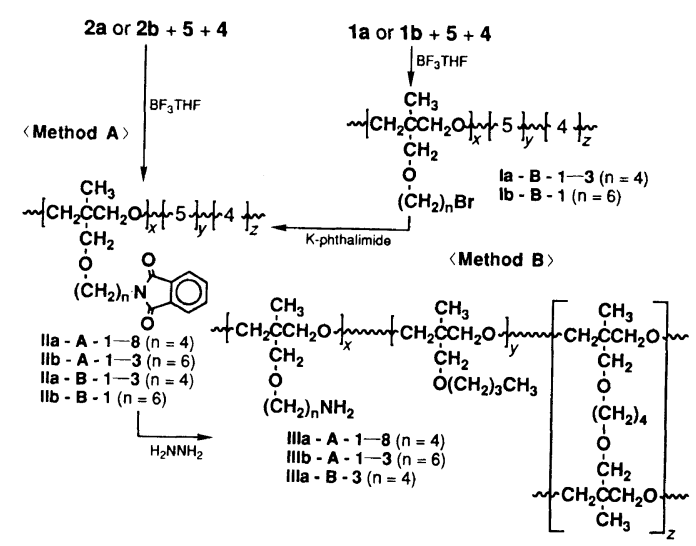

Scheme 2. Synthetic routes of polyoxetanes having a primary amino group at the side chain-end. $\sim[4-4\}$ and $\sim 5$ r r represent the monomeric units of 4 and 5 in polymers, respectively.

in the presence of a trifluoroboran $\left(\mathrm{BF}_{3}\right)$ initiator. These phthalimido groups, moreover, were readily reduced with hydrazine to yield the primary amino group at the side chainend. In this peport, therefore, we describe the preparation and characterization of the uncross- and cross-linked polyoxetanes having the pendant phthalimido and primary amino groups at the side chain-end through moderately long spacers. The synthetic routes of oxetane monomers used in the preparation of various polyoxetanes with a primary amino group are shown in Scheme 1 and the preparation methods of these amine polymers are shown in Scheme 2.

\section{EXPERIMENTAL}

\section{Materials}

Oxetanes 1a, 1b, 4, 5, 6, and 7 and polymers Ia-B-1-3 and Ib-B-1 were prepared according to the methods of literature. ${ }^{4-6}$

$N$-[6-(3-Methyl-3-oxetanyl)-5-oxahexyl]phthalimide (2a); Typical Procedure. Bromide $1 \mathrm{a}(12.7 \mathrm{mmol})$ and potassium phthalimide (PPI) $(13.0 \mathrm{mmol})$ were stirred in $N, N$ dimethylformamide (DMF) $\left(20 \mathrm{~cm}^{3}\right)$ at $80^{\circ} \mathrm{C}$ for $3.5 \mathrm{~h}$. DMF was evaporated and the residue was dissolved in ether $\left(30 \mathrm{~cm}^{3}\right)$. The ether solution was washed with a $5 \%$ sodium hydroxide $(\mathrm{NaOH})$ solution $\left(10 \mathrm{~cm}^{3}\right)$ and water $\left(2 \times 10 \mathrm{~cm}^{3}\right)$ successively, and dried over anhydrous sodium sulfate $\left(\mathrm{Na}_{2} \mathrm{SO}_{4}\right)$. After removing the ether, the residue was dissolved in benzene and placed in a pot connected to a Dean-Stark apparatus containing calcium hydride $(1 \mathrm{~g})$ in the solvent trap. The benzene solution was refluxed for $30 \mathrm{~h}$ and then the solvent was distilled off under reduced pressure. The residue was dried in vacuum to give the oily product 2 a (95\% yield), which was directly used as the monomer of cationic ring-opening polymerization: IR (neat) $3100,3060,3030$, 1615, and 720 (1,2-disubstituted benzene), 1775 and 1710 (phthalimido $\mathrm{C}=\mathrm{O}$ ), 1115 (acyclic ether), and 980 and $835 \mathrm{~cm}^{-1}$ (cyclic ether); ${ }^{1} \mathrm{H}$ NMR $\left(\mathrm{CDCl}_{3}\right) \delta 1.30\left(\mathrm{~s}, 3 \mathrm{H}, \mathrm{CH}_{3}\right), 1.5-2.0$ [m, $4 \mathrm{H}, \mathrm{OCH}_{2}\left(\mathrm{CH}_{2}\right)_{2} \mathrm{CH}_{2} \mathrm{~N}$ ], 3.4-3.6 [total $4 \mathrm{H}: \delta 3.47, \mathrm{~s}, \mathrm{CH}_{2}$ adjacent to the oxetane ring; $\left.\delta 3.50, \mathrm{t}, J=6.8 \mathrm{~Hz}, \mathrm{OCH}_{2}\left(\mathrm{CH}_{2}\right)_{3} \mathrm{~N}\right], 3.72(\mathrm{t}$, $2 \mathrm{H}, J=6.8 \mathrm{~Hz}, \mathrm{CH}_{2}$ adjacent to the phthalimido), 4.32 and 4.88 (AB-q, each $2 \mathrm{H}, J=5.6 \mathrm{~Hz}$, $\mathrm{CH}_{2}$ of the oxetane ring), and $7.6-8.00 \mathrm{ppm}$ (m, 4H, ArH).

Anal. Calcd for $\mathrm{C}_{17} \mathrm{H}_{21} \mathrm{NO}_{4}: \mathrm{C}, 67.27 \% ; \mathrm{H}$, $6.92 \% ; \mathrm{N}, 4.62 \%$. Found: C, $67.06 \% ; \mathrm{H}$, $6.90 \% ; \mathrm{N}, 4.59 \%$.

$N$-[8-(3-Methyl-3-oxetanyl)-7-oxaoctyl]phthalimide $(\mathbf{2 b})$. Obtained from the bromide 1b $(29.0 \mathrm{mmol})$ in a $98 \%$ yield by the same procedure as described for preparing 2a: IR (neat) 3100, 3060, 3030, 1615, and 720 
(1,2-disubstituted benzene), 1775 and 1710 (phthalimido $\mathrm{C}=\mathrm{O}$ ), 1115 (acyclic ether), and 920 and $835 \mathrm{~cm}^{-1}$ (cyclic ether); ${ }^{1} \mathrm{H}$ NMR $\left(\mathrm{CDCl}_{3}\right) \delta 1.2-1.8$ [total $11 \mathrm{H}: \delta 1.30, \mathrm{~s}, \mathrm{CH}_{3}$; $\left.\delta 1.2-1.8, \mathrm{~m}, \mathrm{OCH}_{2}\left(\mathrm{CH}_{2}\right)_{4} \mathrm{CH}_{2} \mathrm{~N}\right], 3.35-$ 3.55 [total $4 \mathrm{H}: \delta 3.45, \mathrm{t}, J=6.2 \mathrm{~Hz}, \mathrm{OCH}_{2}-$ $\left(\mathrm{CH}_{2}\right)_{5} \mathrm{~N} ; \delta 3.46, \mathrm{~s}, \mathrm{CH}_{2}$ adjacent to the oxetane ring], $3.68\left(\mathrm{t}, 2 \mathrm{H}, J=6.8 \mathrm{~Hz}, \mathrm{CH}_{2}\right.$ adjacent to the phthalimide), 3.42 and 4.47 (AB-q, each $2 \mathrm{H}, J=5.7 \mathrm{~Hz}, \mathrm{CH}_{2}$ of the oxetane ring), and 7.6-8.0 ppm (m, 4H, ArH).

Anal. Calcd for $\mathrm{C}_{19} \mathrm{H}_{25} \mathrm{NO}_{4}: \mathrm{C}, 68.83 \% ; \mathrm{H}$, $7.55 \% ; \mathrm{N}, 4.23 \%$. Found: C, $68.28 \% ; \mathrm{H}$, $7.71 \% ; \mathrm{N}, 4.19 \%$.

$N$-[(3-Methyl-3-oxetanyl)methyl] phthalimide (8). Obtained by the reaction between p-toluenesulfonate $7(19.5 \mathrm{mmol})$ and PPI $(20.0 \mathrm{mmol})$ in DMF $\left(30 \mathrm{~cm}^{3}\right)$ at $80^{\circ} \mathrm{C}$ for $6 \mathrm{~h}$. The product 8 was purified by recrystallization from ether: yield $80 \%$; mp $105-106^{\circ} \mathrm{C}$; IR (KBr) 3100, 3060, 3030, 1615, 1495, 1460, and 730 (1,2-disubstituted benzene), 1760 and 1710 (phthalimido $\mathrm{C}=\mathrm{O}$ ), and 975 and $830 \mathrm{~cm}^{-1}$ (cyclic ether); ${ }^{1} \mathrm{H} \mathrm{NMR}\left(\mathrm{CDCl}_{3}\right) \delta 1.36(\mathrm{~s}, 3 \mathrm{H}$, $\left.\mathrm{CH}_{3}\right), 3.87\left(\mathrm{~s}, 2 \mathrm{H}, \mathrm{CH}_{2}\right.$ adjacent to the exetane ring), 4.34 and 4.70 (AB-q, each $2 \mathrm{H}$, $J=6.4 \mathrm{~Hz}, \mathrm{CH}_{2}$ of the oxetane ring), and 7.7-8.0 ppm (m, 4H, ArH).

Anal. Calcd for $\mathrm{C}_{13} \mathrm{H}_{13} \mathrm{NO}_{3}: \mathrm{C}, 67.52 ; \mathrm{H}$, $5.62 ; \mathrm{N}, 6.06 \%$. Found: C, $67.60 \%$; H, 5.59\%; $\mathrm{N}, 5.87 \%$.

3-(6-Amino-2-oxahexyl)-3-methyloxetane (3). To the phthalimide $2 \mathrm{a}(9.4 \mathrm{mmol})$ in ethanol $\left(5 \mathrm{~cm}^{3}\right)$ a solution of hydrazine monohydrate $(41 \mathrm{mmol})$ dissolved in ethanol $\left(5 \mathrm{~cm}^{3}\right)$ was added dropwise at $25^{\circ} \mathrm{C}$. After the complete addition of the hydrazine to $2 \mathrm{a}$, the contents were stirred at $40^{\circ} \mathrm{C}$ for $5.5 \mathrm{~h}$ to form cream-like materials. The solvent was removed by an evaporator and the residue was mixed thoroughly with $30 \mathrm{~cm}^{3}$ of $2 \mathrm{~N} \mathrm{HCl}$ and then filtered to remove phthalic hydrazide. The filtrate was made basic at pH 9 with $\mathrm{NaOH}$, concentrated, and extracted with benzene $\left(2 \times 15 \mathrm{~cm}^{3}\right)$. The combined organic layers were distilled to give the product 3 in a $23 \%$ yield: bp $59-64^{\circ} \mathrm{C}(16 \mathrm{~Pa})$; IR (neat) $3200-2600$ $\left(\mathrm{NH}_{2}\right), 1115$ (acyclic ether), and 980 and $835 \mathrm{~cm}^{-1}$ (cyclic ether); ${ }^{1} \mathrm{H}$ NMR $\left(\mathrm{CDCl}_{3}\right) \delta$ $1.31\left(\mathrm{~s}, 3 \mathrm{H}, \mathrm{CH}_{3}\right), 1.7-1.9\left[\mathrm{~m}, 4 \mathrm{H}, \mathrm{OCH}_{2^{-}}\right.$ $\left.\left(\mathrm{CH}_{2}\right)_{2} \mathrm{CH}_{2} \mathrm{NH}_{2}\right], 1.93$ (s, $2 \mathrm{H}, \mathrm{NH}_{2}$, this signal disappeared by adding $\mathrm{D}_{2} \mathrm{O}$ to the sample solution), $2.73\left(\mathrm{t}, 2 \mathrm{H}, J=6.6 \mathrm{~Hz}, \mathrm{CH}_{2} \mathrm{NH}_{2}\right.$ ), 3.4-3.6 [total 4H: $\delta 3.49, \mathrm{~s}, \mathrm{CH}_{2}$ adjacent to the oxetane ring; $\delta 3.25, \mathrm{t}, J=5.0 \mathrm{~Hz}$, $\left.\mathrm{OCH}_{2}\left(\mathrm{CH}_{2}\right)_{3} \mathrm{NH}_{2}\right]$, and 4.34 and $4.49 \mathrm{ppm}$ (AB-q, each $2 \mathrm{H}, J=5.6 \mathrm{~Hz}, \mathrm{CH}_{2}$ of the oxetane ring).

5,6-Benzo-1-methyl-8,11,3-dioxazatricyclo$\left[5.2 .2 .0^{3,7}\right]$ undec-5-en-4-one (10). To the phthalimide $8(0.2 \mathrm{~g}, 0.865 \mathrm{mmol})$ in a test tube, dry dichloromethane (DCM) $\left(2 \mathrm{~cm}^{3}\right)$ and a diethyl ether- or tetrahydrofuran (THF)-BF ${ }_{3}$ $(1: 1)$ complex $(5 \mathrm{~mol} \%)$ were added successively through a hypodermic or micro syringe under an atomsphere of nitrogen and the contents were stirred at $28^{\circ} \mathrm{C}$ for $30 \mathrm{~h}$. After adding dry triethylamine $\left(0.12 \mathrm{~cm}^{3}\right)$ to the contents, the mixture was stirred at this temperature for additional $2 \mathrm{~h}$. The solvent was evaporated and the oily residue was subjected to column chromatography using $\mathrm{Al}_{2} \mathrm{O}_{3}$ as a stationary phase and $\mathrm{CHCl}_{3}$ as an eluent, followed by recrystallization of the crude product from hexane containing a small portion of DCM to give $\mathbf{1 0}$ as needle crystals in a $42 \%$ yield; $\mathrm{mp}, 168-169^{\circ} \mathrm{C}$; IR $(\mathrm{KBr})$ $3060,1620,1470$, and 800 (1,2-disubstituted benzene), 1720 (cyclic amide $\mathrm{C}=\mathrm{O}$ ), 1260 (C-N), $1100-1000 \mathrm{~cm}^{-1}$ (ether $\left.\mathrm{C}-\mathrm{O}\right) ;{ }^{1} \mathrm{H}$ $\mathrm{NMR}\left(\mathrm{CDCl}_{3}\right) \delta 1.05\left(\mathrm{~s}, 3 \mathrm{H}, \mathrm{CH}_{3}\right), 3.75$ (s, $\left.2 \mathrm{H}, \mathrm{CH}_{2}-\mathrm{N}\right), 4.02$ and $4.15(\mathrm{AB}-\mathrm{q}$, total $4 \mathrm{H}$, $\left.J=8.1 \mathrm{~Hz}, \mathrm{CH}_{2} \mathrm{O}\right), 7.5-7.7(\mathrm{~m}, 3 \mathrm{H}, \mathrm{ArH}$ located at the $m$ - and $p$-positions to the acyl group), and 7.7-7.9 ppm (m, 1H, ArH located at the $o$-position to the acyl group).

Anal. Calcd for $\mathrm{C}_{13} \mathrm{H}_{13} \mathrm{NO}_{3}: \mathrm{C}, 67.52 \% ; \mathrm{H}$, $5.67 \% ; \mathrm{N}, 6.06 \%$. Found: C, $67.29 \% ; \mathrm{H}$, $5.73 \% ; \mathrm{N}, 5.98 \%$.

$N-[2,2-B i s($ hydroxymethyl)propyl $]$ phthalimide (11). The tricyclic product $10(30 \mathrm{mg}$, $0.13 \mathrm{mmol})$ was stirred in THF $\left(2 \mathrm{~cm}^{3}\right)$ 
containing $0.05 \mathrm{~cm}^{3}$ of $0.5 \mathrm{~N} \mathrm{HCl}$ at $20-25^{\circ} \mathrm{C}$ for $2 \mathrm{~h}$. The mixture was extracted with ether and the organic layer was dried over $\mathrm{Na}_{2} \mathrm{SO}_{4}$. The solvent was evaporated and the residue was recrystallized from carbon tetrachloride containing a small portion of DCM to give $11 \mathrm{mg}$ (34\% yield) of 11: mp $117-118^{\circ} \mathrm{C}$; IR (KBr) 3400 and 1035 (alcohol), 3120, 3060, $3030,1620,1470$, and 730 (1, 2-disubstituted benzene), 1770 and 1700 (phthalimido $\mathrm{C}=\mathrm{O}$ ), $1355 \mathrm{~cm}^{-1}(\mathrm{C}-\mathrm{N}) ;{ }^{1} \mathrm{H}$ NMR $\left(\mathrm{CDCl}_{3}\right) \delta 0.88$ (s, $\left.3 \mathrm{H}, \mathrm{CH}_{3}\right), 2.5-3.2(\mathrm{~b}, 2 \mathrm{H}, \mathrm{OH}), 3.38$ and 3.50 (AB-q, each $2 \mathrm{H}, J=12.0 \mathrm{~Hz}, \mathrm{CH}_{2} \mathrm{OH}$ ), $3.83\left(\mathrm{~s}, 2 \mathrm{H}, \mathrm{CH}_{2}-\mathrm{N}\right)$, and $7.7-8.0 \mathrm{ppm}(\mathrm{m}$, 4H, ArH).

Anal. Calcd for $\mathrm{C}_{13} \mathrm{H}_{15} \mathrm{NO}_{4}: \mathrm{C}, 62.64 \%$; $\mathrm{H}, 6.07 \%$; N, 5.62\%. Found: C, 62.67\%; H, $6.22 \% ; \mathrm{N}, 5.44 \%$.

\section{Polymerization}

Cationic Ring-Opening Polymerization of Oxetanes with $\mathrm{BF}_{3} \mathrm{THF}$; Typical Procedure. In a test tube $(20 \phi \times 180), 3.5 \mathrm{~m}^{3}$ of a $1.80 \mathrm{~mol}$ $\mathrm{dm}^{-3}$ solution of $\mathbf{2 a}$ in toluene was placed by a hypodermic syringe under nitrogen, and then $2.1 \mathrm{~cm}^{3}$ of a $3.05 \mathrm{~mol} \mathrm{dm}{ }^{-3}$ solution of 5 in toluene was added similarly. The contents were mixed at $20-25^{\circ} \mathrm{C}$ with $0.75 \mathrm{~cm}^{3}$ of a $0.5 \mathrm{~mol} \mathrm{dm}^{-3}$ solution of a THF-BF $3(1: 1)$ complex $\left(\mathrm{BF}_{3} \mathrm{THF}\right)$ in DCM. The test tube was closed by a ground-glass stopper and kept at $20-25^{\circ} \mathrm{C}$ for $20 \mathrm{~h}$. The contents were poured into methanol $\left(400 \mathrm{~cm}^{3}\right)$ and the precipitate was purified by reprecipitation from toluene to methanol. The final precipitate was collected by decantation and dried in vacuum to give $2.61 \mathrm{~g}$ of the methanol-insoluble fraction of IIa-A-3. Cross-linked polymers were obtained by washing the polymerization product with $20 \%$ aqueous methanol, methanol, and ether successively and then by drying the product in vacuum.

Cationic Ring-Opening Isomerization Polymerization of 10. A test tube containing 10 $(0.2 \mathrm{~g}, \quad 0.78 \mathrm{mmol})$ and 1-benzylthiolanium hexafluoroantimonate ${ }^{7}$ was degassed in vac- cum and then charged with dry nitrogen gas. Dry chlorobenzene $\left(0.3 \mathrm{~cm}^{3}\right)$ was placed into the test tube by a hypodermic syringe under nitrogen and the mixture was left standing in an oil bath at $120^{\circ} \mathrm{C}$ for $10 \mathrm{~h}$. The contents were dissolved in a small portion of THF and poured into a large volume of hexane to precipitate the product polymer. The polymer was dried in vacuum to give $0.21 \mathrm{~g}$ of poly $(8)$ : IR (KBr) 1780 and 1710 (phthalimido $\mathrm{C}=\mathrm{O}$ ), 1110 (ether $\mathrm{C}-\mathrm{O}$ ), and 730 and $720 \mathrm{~cm}^{-1}$ (1,2-disubstituted benzene); ${ }^{1} \mathrm{H}$ NMR $\left(\mathrm{CDCl}_{3}\right)$ $\delta 0.80\left(\mathrm{~s}, 3 \mathrm{H}, \mathrm{CH}_{3}\right), 3.17\left(\mathrm{~s}, 4 \mathrm{H}, \mathrm{OCH}_{2}\right), 3.61$ (s, 2H, $\mathrm{NCH}_{2}$ ), and 8.2-7.2 (m, 4H, ArH).

\section{Polymer Reaction}

Displacement of the Pendant Bromide with PPI; Typical Procedure. Cross-linked polymer Ia-B-3 (1.98 g, about $6.3 \mathrm{mmol}$ of the pendant bromide) was swollen in DMF $\left(15 \mathrm{~cm}^{3}\right)$ and stirred with PPI $(7.2 \mathrm{mmol})$ at $80^{\circ} \mathrm{C}$ for $10 \mathrm{~h}$. After a large portion of DMF was evaporated, the residue was washed with water and methanol successively and dried in vacuum to give the product polymer IIa-B-3 in a $92 \%$ yield. Uncross-linked polymers were obtained by removing DMF from the reaction mixture and then by reprecipitating the residue from DCM to methanol.

Hydrazinolysis of the Pendant Phthalimide; Typical Procedure. Cross-linked polymer IIaB-3 $(2.21 \mathrm{~g}$, about $5.9 \mathrm{mmol}$ of the phthalimide) was stirred with hydrazine monohydrate $(41 \mathrm{mmol})$ in ethanol $\left(16 \mathrm{~cm}^{3}\right)$ at $40^{\circ} \mathrm{C}$ for $6 \mathrm{~h}$. The ethanol was evaporated and the residue was made basic at $\mathrm{pH} 9$ with $\mathrm{NaOH}$. The product polymer was collected by filtration, washed with water and methanol successively, and dried in vacuum to give $1.45 \mathrm{~g}$ of IIIa-B-3. In the case of homopolymers, IIIa-A-1 and IIIb-A-1, the reaction mixture was acidified at $\mathrm{pH} 3$ with $3 N \mathrm{HCl}$ and filtered. The filtrate was made basic at $\mathrm{pH} 9$ with $\mathrm{NaOH}$ and concentrated to an adequate volume. The concentrated aqueous solution was placed in a 
bag made of a membrane sheet $(102 \times 152 \mathrm{~mm}$, pore size $2.4 \mathrm{~nm}$ ), and inorganic impurities were removed from the solution by dialysis at $25^{\circ} \mathrm{C}$ for $30 \mathrm{~h}$ against distilled water $\left(3 \times 200 \mathrm{~cm}^{3}\right)$. The resultant aqueous solution was freezedried to give the amine polymer.

\section{Measurements}

IR spectra of the products were recorded on a JASCO A-202 spectrometer and ${ }^{1} \mathrm{H}$ NMR on a $100 \mathrm{MHz}$ instrument (JEOL FX-100S) using $\mathrm{CDCl}_{3}$ as a solvent and TMS as an internal standard at $25^{\circ} \mathrm{C}$. Molecular-weight measurements were made by gel-permeation chromatography (GPC) using columns G4000H8 and G2500HXL (each $7.8 \phi \times 300$, $\mathrm{TOSOH})$ arranged in a series and THF as the solvent $\left(0.8 \mathrm{~cm}^{3} \mathrm{~min}^{-1}\right)$. The content of the pendant amino group was determined as usual by non-aqueous titration using hydroperchloric acid in methanol with an Eosine $Y$ indicator.

\section{RESULTS AND DISCUSSION}

\section{Preparation of Polyoxetanes Having a Primary Amino Group at the Side Chain-End}

Oxethanes with the pendant amino group, such as 3, are not allowed to polymerize with a $\mathrm{BF}_{3} \mathrm{THF}$ initiator. Therefore, the preparation of polyoxetanes, IIa-As and IIb-As, with the pendant phthalimido group is the main step for obtaining the amine polymers, IIIa-As and IIIlb-As, by the Gabriel synthesis method. The preparation of phthalimide-containing polyoxetanes was carried out by the two procedures of Methods A and B, as shown in Scheme 2.

Cationic Ring-Opening Polymerization of Oxetanes by Method A. In the Method A, polyoxetanes, IIa-As and IIb-As, were obtained by the cationic ring-opening polymerization of oxetanes $\mathbf{2 a}$ and $\mathbf{2 b}$ in toluene at $20-30^{\circ} \mathrm{C}$ with $\mathrm{BF}_{3} \mathrm{THF}$. The high purity of the viscous oily products $\mathbf{2 a}$ and $\mathbf{2 b}$, obtained after modified post-treatment without purification by recrystallization or distillation, was confirmed from their ${ }^{1} \mathrm{H}$ NMR spectra and elemental analysis data. In the polymerization of $\mathbf{2 a}$ and $2 \mathbf{b}$, oxetanes 4 and 5 were also used, respectively, as a cross-linking agent and hydrophobic monomer unit. The results are summarized in Table I for the preparation of the pendant-phthalimide-containing polyoxetanes by Method A. The contents of monomeric unit of the product polymers were estimated by ${ }^{1} \mathrm{H}$ NMR spectroscopy for the uncross-linked polymers and by elemental analysis for the cross-linked polymers.

For the typical spectra of the product polymers, the ${ }^{1} \mathrm{H}$ NMR spectrum of IIa-A-1 is shown in Figure 1 together with that of the corresponding monomer, $\mathbf{2 a}$, and the IR spectrum of cross-linked polymer IIa-A-4 is shown in Figure 2 along with those of $\mathbf{3}$ and the corresponding polymer IIIa-A-4, obtained by hydrazinolysis of the IIa-A-4. The signals in Figures $1 \mathrm{~A}$ and $1 \mathrm{~B}$ are assigned to the corresponding protons of IIa-A-1 and $\mathbf{2 a}$, respectively. In a comparison between the ${ }^{1} \mathrm{H}$ NMR spectra $1 \mathrm{~A}$ and $1 \mathrm{~B}$, the AB-quartet due to the cyclic methylene protons $\left(\mathrm{H}^{\mathrm{c}}\right)$ and singlets due to the neighboring methylene $\left(\mathrm{H}^{\mathrm{f}}\right)$ and methyl protons $\left(\mathrm{H}^{\mathrm{h}}\right)$ for the oxetane ring of 2a appear as the signals $\mathrm{H}^{\mathrm{c}}, \mathrm{H}^{\mathrm{f}}$, and $\mathrm{H}^{\mathrm{h}}$ of IIa-A-1 at the higher magnetic field site after the ring-opening polymerization of $\mathbf{2 a}$. Such findings were also generally observed for other analogues oxetane derivatives prepared previously by us. ${ }^{5}$ Chemical shift values and patterns of the signals for the other protons in 2a resemble those of the corresponding protons in IIa-A-1. In the IR spectrum of IIa-A-4 (Figure 2A), the IR bands at 980 and $835 \mathrm{~cm}^{-1}$ assignable to the cyclic ether of the corresponding monomer 2a disappeared completely, but the strong bands appeared at 1772 and $1715 \mathrm{~cm}^{-1}$ due to the phthalimido group and at $1110 \mathrm{~cm}^{-1}$ due to the ether linkage of the polymer network.

In the polymerization of $\mathbf{2 a}$ or $\mathbf{2 b}$ with $\mathbf{4}$, cross-linked polymers were obtained with easy handling by filtration and unchanged monomer 
Table I. Preparation of phthalimide-containing polyoxetanes ${ }^{\mathrm{a}}$

\begin{tabular}{|c|c|c|c|c|c|}
\hline \multirow{4}{*}{ Entry } & \multirow{4}{*}{$\begin{array}{c}\text { Monomer } \\
\text { (Mole ratio) }\end{array}$} & \multirow{4}{*}{$\frac{[\mathrm{OR}]_{0}^{\mathrm{c}}}{\mathrm{moldm}^{-3}}$} & \multicolumn{3}{|c|}{ Polymer } \\
\hline & & & \multirow{3}{*}{ Name } & \multirow{3}{*}{$\frac{\text { Yield }}{w t \%}$} & \multirow{3}{*}{$\frac{4^{\mathrm{d}}}{\mathrm{mol} \%}$} \\
\hline & & & & & \\
\hline & & & & & \\
\hline 1 & $2 \mathbf{a}^{\mathrm{b}}$ & 1.8 & IIa-A-1 & $85^{\mathrm{f}}$ & 0 \\
\hline 2 & $\mathbf{2 a}+5(67 / 33)$ & 2.1 & IIa-A-2 & $61^{g}$ & $33^{\mathrm{e}}$ \\
\hline 3 & $\mathbf{2 a}+\mathbf{5}(50 / 50)$ & 2.3 & IIa-A-3 & $89^{\mathrm{h}}$ & $50^{\mathrm{e}}$ \\
\hline 4 & $2 a+4(84 / 16)$ & 2.6 & IIa-A-4 & 90 & 21 \\
\hline 5 & $2 a+4(75 / 25)$ & 3.5 & IIa-A-5 & 99 & 23 \\
\hline 6 & $2 a+4(74 / 26)$ & 0.9 & IIa-A-6 & 42 & $31^{\mathrm{e}}$ \\
\hline 7 & $\mathbf{2 a}+\mathbf{4}(70 / 30)$ & 2.5 & IIa-A-7 & 93 & 33 \\
\hline 8 & $\mathbf{2 a}+\mathbf{4}(55 / 45)$ & 2.5 & IIa-A-8 & 89 & 43 \\
\hline 9 & $\mathbf{2 b}$ & 1.2 & IIb-A-1 & $43^{\mathrm{i}}$ & 0 \\
\hline 10 & $\mathbf{2 b}+\mathbf{4}(85 / 15)$ & 2.5 & IIb-A-2 & 92 & 22 \\
\hline 11 & $\mathbf{2 b}+\mathbf{4}(75 / 25)$ & 2.7 & IIb-A-3 & 92 & 29 \\
\hline
\end{tabular}

a In toluene at $20-25^{\circ} \mathrm{C}$ for $20 \mathrm{~h}$ with $2-3 \mathrm{~mol} \%$ of $\mathrm{BF}_{3} \mathrm{THF}$ to the total of oxetane ring.

b With $8 \mathrm{~mol} \%$ of $\mathrm{BF}_{3}$ THF.

c Initial concentration for the total of oxetane ring.

d Monomeric unit fraction of $\mathbf{4}$ was estimated from elemental analysis data for the $\mathrm{C}$ and $\mathrm{N}$ atoms of the product polymer.

${ }^{\mathrm{e}}$ The monomeric unit content of 5 estimated from integral intensity by ${ }^{1} \mathrm{H}$ NMR spectroscopy.

$\mathrm{f}^{-\mathrm{i}}$ Molecular weights $\left(M_{\mathrm{GPC}}\right)$ were as follows: f, 24500; $\mathrm{g}, 41600 ; \mathrm{h}, 30700$; and i, 5700.

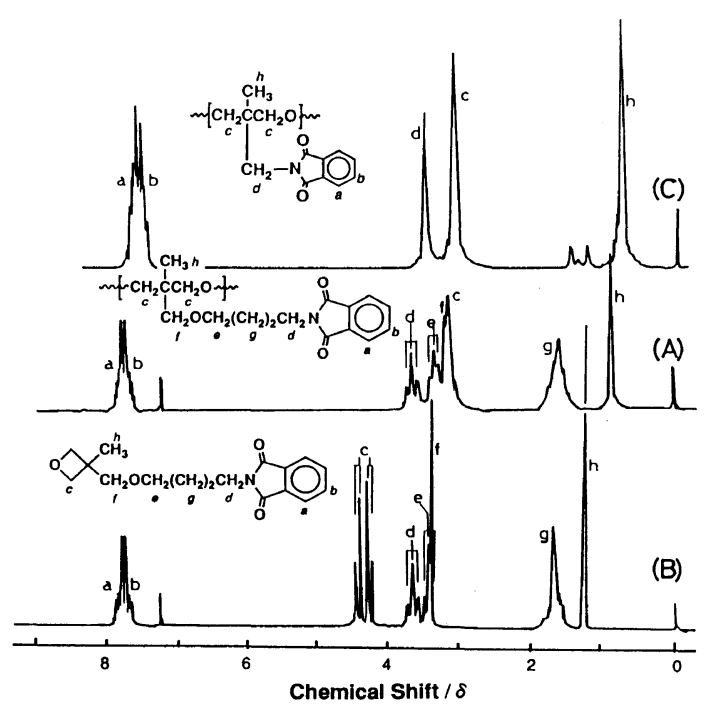

Figure 1. ${ }^{1} \mathrm{H}$ NMR spectra of (A) IIa-A-1, (B) 2a, and (C) $\operatorname{poly}(\mathbf{8})$.

$\mathbf{2 a}$ or $\mathbf{2 b}$ was recovered from the filtrate, while 4 was hardly detected in the filtrate. Therefore, the degree of cross-linking must be reestimated

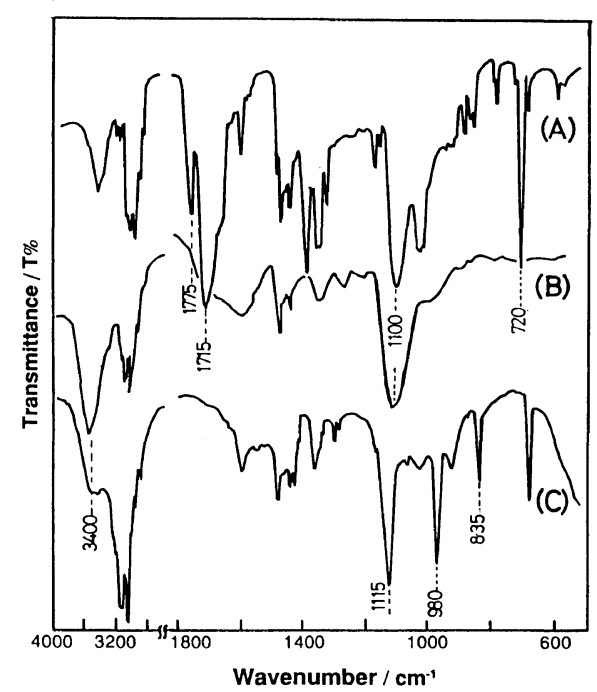

Figure 2. IR spectra of (A) IIa-A-4, (b) IIIa-A-4, and (C) 3.

for the product polymers. The monomeric unit content for 4 in the product polymer is estimated to be higher than that in feed. The cross-linked polymers did not seem to contain 
such organic compounds as toluene and methanol used as a polymerization solvent or a washing solvent, as suggested from the ${ }^{1} \mathrm{H}$ NMR spectra, e.g., Figure 1A, of the uncross-linked polymers dried thoroughly in vacuum. The degrees of cross-linking of the product polymers, IIa-As and IIb-As, were reestimated from elemental analysis data for the carbon and nitrogen atoms, and then the theoretical values of the elemental content were calculated for the product polymers, which were assumed to be composed of $\mathbf{2} \mathbf{a}$ or $\mathbf{2} \mathbf{b}$ and 4 in these reestimated degrees of cross-linking. These values are fairly close to the observed ones (Table III), indicating that the product polymers scarcely contained any organic impurities due to the solvents used. However, the observed elemental contents for IIIa-As and IIIb-As, obtained by hydrazinolysis of the corresponding phthalimide polymers, are somewhat different from the theoretical contents (vide infra). These results for the reestimated monomeric unit contents of $\mathbf{4}$ are shown in Figure 3 together with results not listed in Table I. In each product polymer, the mole fraction of monomeric unit for 4 shows a tendency to be appreciably higher relative to that of the charged 4.

The initial total concentration $[\mathrm{OR}]_{0}$ for the oxetane ring of the charged monomers must be set about $2.0 \mathrm{moldm}^{-3}$. When the $[\mathrm{OR}]_{0}$ was set at 0.9 to $1.2 \mathrm{~mol} \mathrm{dm}^{-3}$, the product polymers IIa-A-6 and IIb-A-1, which were collected as a methanol-insoluble fraction, were obtained in low yields up to $43 \%$ (Entries 6 and 9), and the main component of these methanol-soluble fractions was the unchanged monomer $\mathbf{2 a}$ or $\mathbf{2 b}$. Additionally, the GPCaverage molecular weight $\left(M_{\mathrm{GPC}}\right)$ of IIb-A-1 was considerably lower than that of IIa-A-1, obtained in a $85 \%$ yield using on increased amount of $\mathrm{BF}_{3} \mathrm{THF}$ such as $8 \mathrm{~mol} \%$. The results may be ascribed to the low propagation rate constants for the phthalimide-containing monomers. Furthermore, the product polymer IIa-A-6 was soluble in such solvents as DCM,

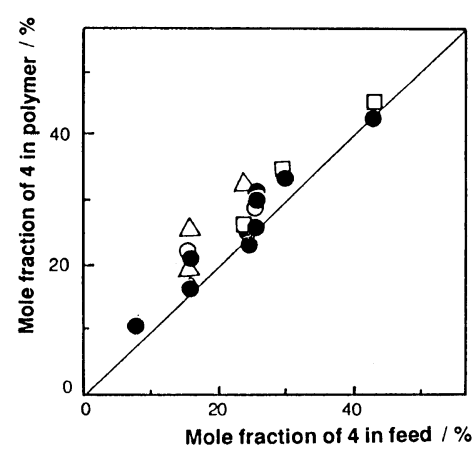

Figure 3. Relationship between the mole fraction of 4 in polymer and that of 4 in feed: (O) poly(2a-co-4)s and ( $\square$ ) their hydrazinolysis products; $(\bigcirc)$ poly $(2 \mathbf{b}-\mathrm{co}-\mathbf{4}) \mathrm{s}$ and $(\triangle)$ their hydrazinolysis products.

chloroform, and benzene, in spite of containing $31 \mathrm{~mol} \%$ the cross-linking agent in the polymer network. This polymer, which was purified by reprecipitating it from DCM to methanol, contained no unchanged oxetane ring, and monomeric unit fractions were estimated by ${ }^{1} \mathrm{H}$ NMR using $\mathrm{CDCl}_{3}$ as a solvent. As to the preparation of divinylbenzene-cross-linked polystyrene resins, it is known that a macroporous network is formed with the generation of considerable porosity under the preparation conditions using large quantities of cross-linking agent up to about $20 \mathrm{~mol} \%$ in the solvent which solvates both monomer and polymer. ${ }^{8}$ Probably, our polyether network was also formed with the generation of wide meshes when a large amount of the solvent was used relative to the amount of the oxetane monomers, i.e., at the low $[\mathrm{OR}]_{0}$. Such a network could contain the solvent abundantly so as to be dissolved in it, although the cross-linking agent 4 was incorporated in the network in the considerable amount of $31 \mathrm{~mol} \%$, indicating that the cross-linked polymers obtained in this study have a fully expandable, soft polyether network and so are swellable with the organic solvents used.

Hydrazinolysis of the Pendant Phthalimido Group. The pendant phthalimido groups of the IIa-As and IIb-As were warmed with an excess of hydrazine monohydrate in ethanol at $40^{\circ} \mathrm{C}$ 
Table II. Preparation of polyoxetanes having the pendant primary amino group by hydrazinolysis of the corresponding phthalimide ${ }^{\mathrm{a}}$

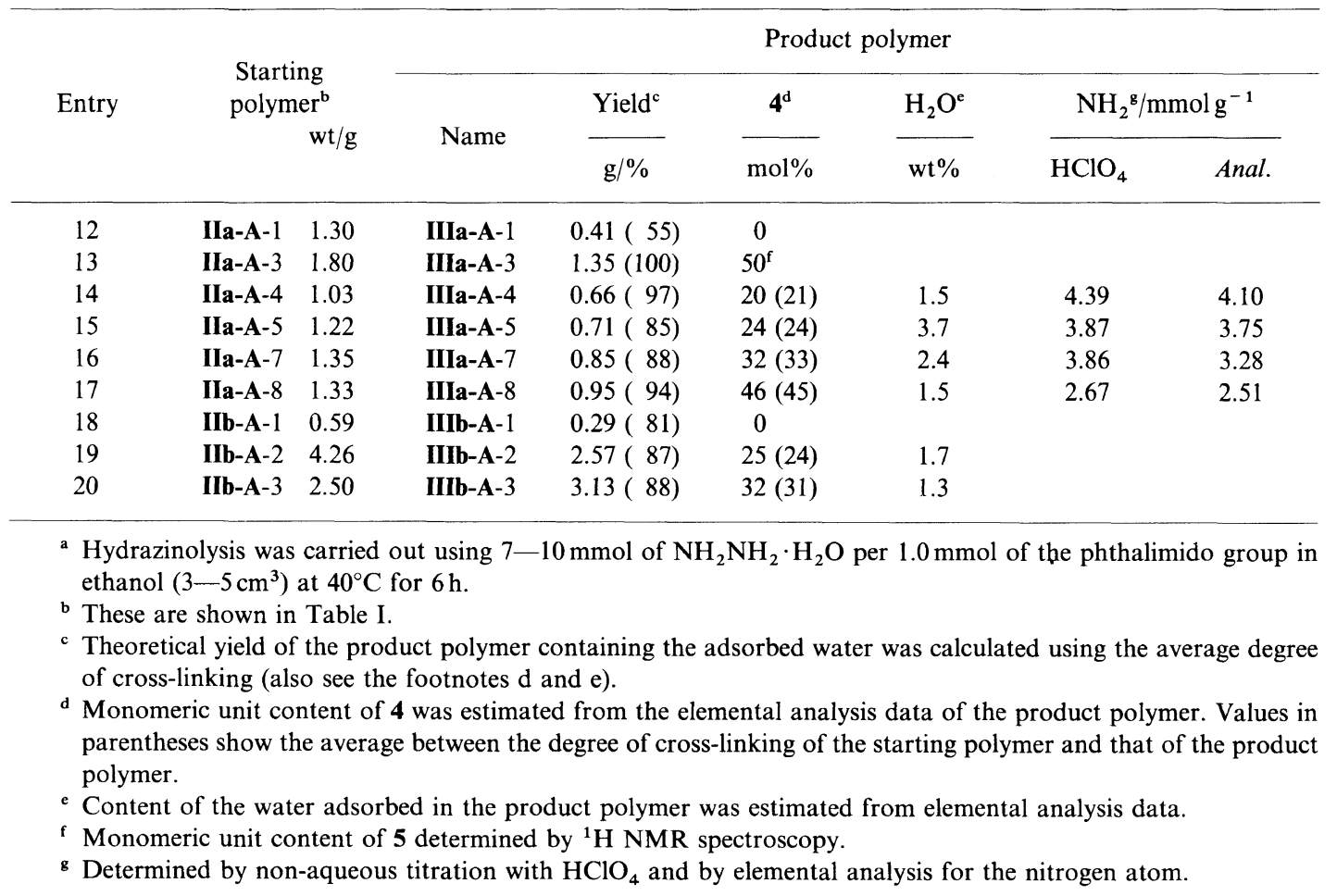

to be converted to the corresponding primary amino groups of IIIa-As and IIIb-As. The results of the hydrazinolysis are summarized in Table II. Cross-linked polymers were obtained in good yields with easy handling such as filtration, and uncross-linked copolymers, e.g., IIIa-A-3, were purified by reprecipitating the raw product polymers from DCM to methanol. However, homopolymers, IIIa-A-1 and IIIb-A1 , were soluble in water and methanol and so must be separated from inorganic impurities by dialysis at room temperature against distilled water. The monomeric unit content for 4 or 5 of the product polymer was also reestimated in the same manner as described in Table I. In each Entry of Table I, the degree of cross-linking of the monomeric unit 4 in the amine polymer seems fairly close to that of the corresponding phthalimide polymer. The theoretical elemental contents required for the amine polymers were calculated using the reestimated degrees of cross-linking for $\mathbf{4}$, assuming that the amine polymers contained no organic impurities such as the polymerization- and washing-solvents as suggested from the results of the ${ }^{1} \mathrm{H}$ NMR spectra of the amine polymers dried thoroughly in vacuum (Table III). However, the calculated contents did not agree with the corresponding observed ones, especially for carbon content. The deviation between the calculated and observed contents is considered to be ascribable to the slight amounts of the moisture adsorbed on the amine polymers. The corresponding amine-containing homopolymers were readily soluble in water due to the hydrophilicity of the pendant amino group, which can make hydrogen bonds with water molecules and generate ammonium cations in water for a part of the amino groups. In fact, homopolymers, IIIa-A-1 and IIIb-A-1, 
Table III. Elemental analysis data of phthalimide- and amino-containing cross-linked polyoxetanes obtained by Method A

\begin{tabular}{|c|c|c|c|c|c|c|}
\hline \multirow{3}{*}{ Polymer name } & \multicolumn{6}{|c|}{ Anal $/ \%$} \\
\hline & \multicolumn{3}{|c|}{ Found } & \multicolumn{3}{|c|}{ Calcd $^{\mathrm{a}}$} \\
\hline & $\mathrm{C}$ & $\mathrm{H}$ & $\mathrm{N}$ & $\mathrm{C}$ & $\mathrm{H}$ & $\mathrm{N}$ \\
\hline IIa-A-4 & 66.55 & 7.48 & 3.73 & 66.89 & 7.58 & 3.79 \\
\hline IIa-A-5 & 66.45 & 7.52 & 3.69 & 66.87 & 7.63 & 3.68 \\
\hline IIa-A-7 & 66.51 & 7.72 & 3.25 & 66.64 & 7.93 & 3.25 \\
\hline IIa-A-8 & 66.03 & 8.31 & 2.79 & 66.43 & 8.23 & 2.73 \\
\hline IIb-A-2 & 67.96 & 7.99 & 3.47 & 68.17 & 8.08 & 3.46 \\
\hline IIb-A-3 & 67.27 & 8.30 & 3.18 & 67.93 & 8.23 & 3.21 \\
\hline IIIa-A-4 & 62.15 & 10.63 & 5.75 & 63.11 & 10.82 & 5.89 \\
\hline IIIa-A-5 & 60.93 & 10.70 & 5.26 & 63.24 & 10.78 & 5.50 \\
\hline IIIa-A-7 & 61.97 & 10.41 & 4.60 & 63.49 & 10.70 & 4.75 \\
\hline IIIa-A-8 & 62.92 & 10.19 & 3.52 & 63.88 & 10.56 & 3.56 \\
\hline IIIb-A-2 & 64.34 & 11.52 & 4.79 & 65.45 & 11.13 & 4.87 \\
\hline IIIb-A-3 & 64.58 & 11.11 & 4.26 & 65.41 & 11.02 & 4.34 \\
\hline
\end{tabular}

a For the phthalimide polymers, composed of $\mathbf{2 a}$ (or $\mathbf{2 b}$ ) and $\mathbf{4}$ with the degrees of cross-linking reestimated from the contents of $\mathrm{C}$ and $\mathrm{N}$ atoms. Obtained similarly for the amine polymers. Also see the text.

dissolved in water indicated basicity of $\mathrm{pH} 7.5$ to 8.5 , and their $\mathrm{p} K_{\mathrm{a}}$ were estimated to be 1.9 and 3.4, respectively, by titration with aqueous $\mathrm{NaOH}$, although, in general, methyl- and ethylamines and monoalkylamines with longer alkyl chains have their $\mathrm{p} K_{\mathrm{a}}$ around 10.5 . The lowered basicity of the amine polymer in water may be ascribed to preventing the generation of the ammonium cations in a high density in the polymer matrices, since the cations immobilized densely in the matrices repulse each other more strongly compared with those of ordinary organic amines capable of moving freely in aqueous solution.

The ${ }^{1} \mathrm{H}$ NMR spectrum of amine polymer IIIa-A-3 is shown in Figure 4 to represent amine polymers besides that of $\mathbf{3}$. In Figure $4 \mathrm{~A}$, compared with Figure $1 \mathrm{~A}$, the aromatic protons of the phthalimido group are not observed and the methylene protons $\left(\mathrm{H}^{\mathrm{d}}\right)$ adjacent to the amino group resonate at lower chemical shift than that of the corresponding methylene protons adjacent to the phthalimido group. The spectrum of Figure 4A is similar to that of Figure $4 \mathrm{~B}$, which is shown for a

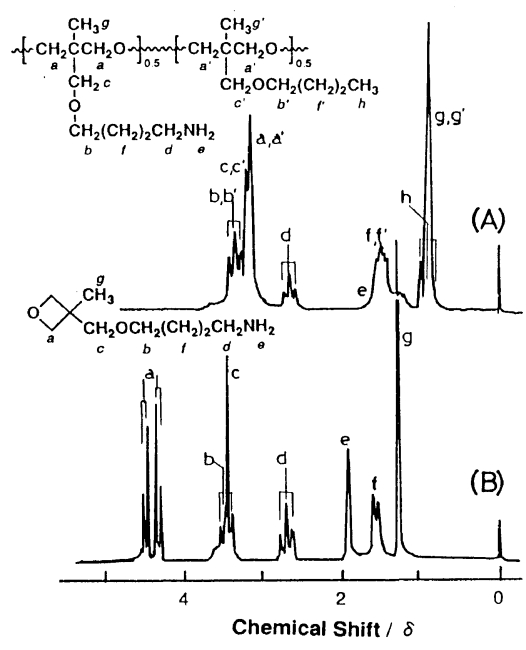

Figure 4. ${ }^{1} \mathrm{H}$ NMR spectra of (A) IIIa-A-3 and (B) 3 .

model compound of the monomeric unit of the pendant-amine-containing polymers, although the signals of the methylene and methyl groups of the oxetane ring are different from those of the polymer main chain.

To examine the cleavage of ether linkages of the polymer and side chains during hydrazino- 
Table IV. Preparation of polyoxetanes by Method B ${ }^{a}$

\begin{tabular}{|c|c|c|c|c|c|}
\hline \multirow{3}{*}{ Entry } & \multirow{3}{*}{ Starting polymer ${ }^{b}$} & \multicolumn{4}{|c|}{ Product polymer } \\
\hline & & \multirow{2}{*}{ No. } & \multirow{2}{*}{$\frac{\text { Yield }}{\%}$} & \multirow{2}{*}{$\frac{4}{\mathrm{~mol} \%}$} & \multirow{2}{*}{$10^{-4} M_{\mathrm{GPC}}$} \\
\hline & & & & & \\
\hline 21 & Ia-B-1 (1a) & IIa-B-1 & 74 & 0 & 4.16 \\
\hline 22 & Ia-B-2 $(1 \mathbf{a}+5,46 / 54)$ & IIa-B-2 & 74 & $54^{\mathrm{d}}$ & 3.57 \\
\hline 23 & Ia-B-3 $(\mathbf{1 a}+\mathbf{4}, 75 / 25)$ & IIa-B-3 & $92^{\mathrm{g}}$ & $20^{\mathrm{e}}$ & - \\
\hline 24 & IIa-B-3 $(2 \mathbf{a}+\mathbf{4}, 80 / 20)^{c}$ & IIIa-B-3 & $95^{\mathrm{g}}$ & $24^{f}(3.7)$ & - \\
\hline 25 & Ib-B-1 (1b) & IIb-B-1 & 92 & 0 & 7.08 \\
\hline
\end{tabular}

a $1.2 \mathrm{mmol}$ of PPI per $1.0 \mathrm{mmol}$ of the pendant bromine atom was used in $8-10 \mathrm{~cm}^{3}$ of DMF per $1.0 \mathrm{~g}$ of the starting polymer at $80^{\circ} \mathrm{C}$ for $8-10 \mathrm{~h}$.

b Monomers and charge ratios used for preparing polymers, Ia-B-1-3 and Ib-B-1, with the pendant bromine atom are given in parentheses.

c Polymer with the pendant phthalimido group, obtained in Entry 23, was used. Reaction conditions were presented in Table II.

${ }^{d}$ Monomeric unit fraction of 5 determined by ${ }^{1} \mathrm{H}$ NMR spectroscopy.

e Determined from analytical data; C, $66.25 \% ; \mathrm{H}, 7.46 \% ; \mathrm{Br}, 0.00 \% ; \mathrm{N}, 3.75 \%$.

f Determined from analytical data: $\mathrm{C}, 60.78 \% ; \mathrm{H}, 10.18 \% ; \mathrm{N}, 5.30 \%$. Figures in parenthesis show the content of moisture $(\mathrm{wt} \%)$ in the product polymer.

g Theoretical yield was calculated based on the estimated contents of the monomeric unit 4 and of the moisture for the product polymer.

lysis, poly(6) (the structure of $\mathbf{6}$ is shown in Scheme 1) was treated with hydrazine monohydrate under reaction conditions comparable to the hydrazinolysis conditions for the phthalimide-containing polymers. The GPC chromatogram of the examined poly(6) was close to that of the polymer recovered almost quantitatively after treatment with hydrazine, i.e., the original poly $(6)$ had $M_{\mathrm{GPC}} 1.11 \times 10^{4}$ $\left(M_{w} / M_{n} 2.65\right)$ and the recovered polymer $M_{\mathrm{GPC}}$ $1.22 \times 10^{4}\left(M_{w} / M_{n} 1.99\right)$. The spectra of these polymers also coincided with each other.

Displacement of the Pendant Bromide Group with PPI by Method B. Polymers, IIa-Bs and IIb-Bs, having the pendant phthalimido group through long spacers such as 2-oxahexa- and 2-oxaoctamethylenes were smoothly obtained by the displacement of the pendant bromine atoms of Ia-B-1-3 and Ib-B-1 with the phthalimido group of PPI in DMF at $80^{\circ} \mathrm{C}$. The IR and ${ }^{1} \mathrm{H}$ NMR spectra of the product polymers coincided, respectively, with those of the product polymers obtained by Method A. The results of these displacement reactions are shown in Table IV. The phthalimido groups were smoothly and completely reduced by hydrazinolysis to give the corresponding primary amino groups in fairly good yield, as exemplified for the hydrazinolysis of IIa-B-3.

\section{Influence of Specers on Ring-Opening Polym- erization and Polymer Reaction}

Up to this time, we thought that the Methods A and $\mathrm{B}$ are general procedures for obtaining the phthalimide-containing polyoxetanes with spacers of differing length. As shown in Scheme 3 , however, these methods were quite ineffective on the ring-opening polymerization of oxetane 8 with $\mathrm{BF}_{3}$ and on the displacement of the pendant $p$-toluenesulfonate of poly(7) with PPI. This indicates the influence of the spacer on the reactivities of an oxetane ring and the pendant substrate of a polyoxetane. Therefore, the role of the spacer may be further clarified by showing these results about 8 and poly(7) in this section. Thus, the oxetane 8 was mixed with $1 \mathrm{~mol} \%$ of $\mathrm{BF}_{3}$ THF and left stand in the same manner as described above 


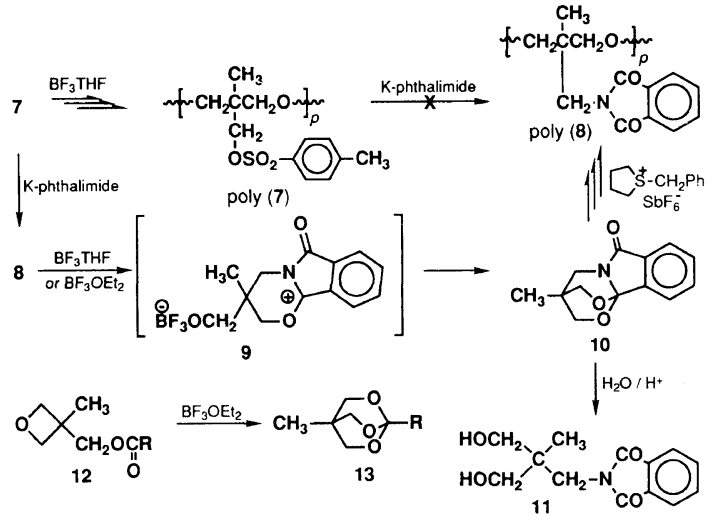

Scheme 3. Reaction routes of 7 and 8 .

for the polymerization of oxetanes. After $24 \mathrm{~h}$ standing at $0^{\circ} \mathrm{C}$, an aliquot was withdrawn from the mixture by means of a hypodermic syringe under nitrogen to be subjected to ${ }^{1} \mathrm{H}$ NMR spectroscopic measurements (Figure 5). This spectrum is shown in Figure $5 \mathrm{~A}$ which is much different from that of $\mathbf{8}$ as shown in Figure 5C. A few drops of $\mathrm{D}_{2} \mathrm{O}$ were added to the aliquot at room temperature. The spectrum of the resultant solution is presented in Figure 5B. The signals of the spectra of Figures $5 \mathrm{~A}$ and $5 \mathrm{~B}$ were assigned to those of the products $\mathbf{1 0}$ and $\mathbf{1 1}$, respectively, the structures of which were also confirmed by the authentic samples. Previously it was reported that oxetanes 12 with the acyloxymethyl pendant at the $\mathrm{C}-3$ position gave 2,6,7-trioxabicyclo[2.2.2] octanes (13) in DCM at $0^{\circ} \mathrm{C}$ in the presence of $\mathrm{BF}_{3} .{ }^{9}$ According to this report, the reaction mechanism from 8 to $\mathbf{1 0}$ may be as follows: the methylene carbon atom of the oxetane ring of $\mathbf{8}$ is attacked intramolecularly in the presence of $\mathrm{BF}_{3}$ by the carbonyl oxygen atom of the phthalimido group to form the bicyclic zwitterion intermediate 9 , but not intermolecularly by the cyclic ether oxygen atom of another $\mathbf{8}$. The paired ions of the zwitterion 9 linked to each other intramolecularly to give the carbon-oxygen covalent bond of the tricyclic product 10. This was readily hydrolyzed

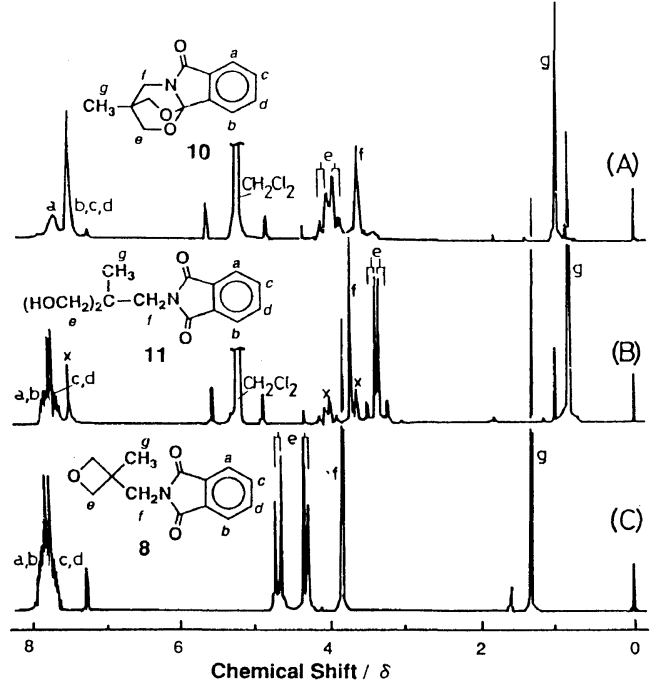

Figure 5. ${ }^{1} \mathrm{H}$ NMR spectra of (A) an aliquot taken from the resultant solution of $\mathbf{8}$ left standing in DCM at room temperature for $20 \mathrm{~h}$, (B) the reaction mixture containing the main product 11 obtained by adding $\mathrm{D}_{2} \mathrm{O}$ to the aliquot, and (C) the solution of $\mathbf{8}$ in $\mathrm{CDCl}_{3}$.

with the added water in the presence of a protonic acid, which was generated from $\mathrm{BF}_{3}$ and the water. Therefore, the oxetane 8 could not be converted to the corresponding polymer by ring-opening polymerization with $\mathrm{BF}_{3}$. Compared with the reaction type of the carboxylic esters 12 in the presence of $\mathrm{BF}_{3}$, the p-toluenesulfonate 7 was polymerized with $1 \mathrm{~mol} \%$ of $\mathrm{BF}_{3} \mathrm{THF}$ to give the corresponding polymer in a $76 \%$ yield. This indicates that the sulfonyl oxygen atom of the tosyloxy group of 7 does not attack intramolecularly the methylene carbon of the oxetane ring, presumably due to avoiding the formation of an unstable zwitterion intermediate with a five-valent sulfur atom. Furthermore, the pendant $p$-toluenesulfonate group of poly(7) was not displaced by PPI to be converted to the phthalimido group of $\operatorname{poly}(\mathbf{8})$. The $p$-toluenesulfonate group of 7 was readily replaced by the corresponding phthalimido residue. The pendant methylene carbon atom of poly(7) resembles that of the neopentyl group which is remarkably unsusceptible to the 
$S_{N} 2$ reaction. These findings show that the degree of steric hindrance is more or less relaxed around the methylene carbon atom adjacent to the oxetane ring compared with that around the neopentyl-like methylene carbon atom adjacent to the quaternary carbon atom of the polymer main chain, i.e., the quaternary carbon atom of the oxetane ring takes a molecular orbital that is somewhat different from the ordinary $s p^{3}$ hybrid orbital.

Thus, the desired polymer product, $\operatorname{poly}(\mathbf{8})$, was not obtained by the cationic ring-opening polymerization of $\mathbf{8}$ in the presence of $\mathrm{BF}_{3}$ or by the polymer reaction of the $p$-toluenesulfonate of poly(7) with PPI. Fortunately, however, tricyclic product $\mathbf{1 0}$ was converted almost quantitatively to the poly $(8)$ with $M_{\mathrm{GPC}}$ about 4000 by cationic ring-opening isomerization polymerization using 1-benzylthiolanium hexafluoroantimonate in chlorobenzene at $120^{\circ} \mathrm{C}$ for $10 \mathrm{~h}$, according to the reported procedure. ${ }^{7}$ The structure of poly $(\mathbf{8})$ was confirmed by its ${ }^{1} \mathrm{H}$ NMR (Figure 1C) and IR spectra.

In conclusion, desired polyoxetanes with a primary amino group through the moderately long spacers were prepared from the corresponding phthalimide-containing polymers by both of methods A and B. The degree of hydrophilicity of the amino polymer could be changed by varying the mole fraction of the hydrophobic monomer $\mathbf{5}$ in the copolymer. At this point we find it difficult to judge which is better Methods A or B, since the polymers obtained by Methods A and B seem similar to each other as to their IR and ${ }^{1} \mathrm{H}$ NMR spectra and elemental analysis data. For the merits and demerits of Methods A and B, we mentioned that the polymerizations of $\mathbf{2} \mathbf{a}$ and $\mathbf{2} \mathbf{b}$ never contain the bromide group, which may be contained as an unchanged pendant substrate in the product polymer obtained by Method B depending on the reaction conditions, although the purification of the phthalimido monomers $\mathbf{2 a}$ and $\mathbf{2 b}$ is somewhat troublesome. In this study, other desired products, $\operatorname{poly}(\mathbf{8})$ and cross-linked analogues, could not be obtained by Method A or B. However, the primary amino group anchored to the soft, expandable polyoxetane network through the moderately long spacers will be examined for use as a key substrate for preparing functional polymers.

\section{REFERENCES}

1. M. Motoi, K. Shimamura, C. Shimamura, S. Muramoto, S. Kanoh, and H. Suda, Bull. Chem. Soc. Jpn., 62, 2553 (1989).

2. M. Motoi, E. Saito, S. Kyoda, N. Takahata, S. Nagai, and A. Arano, Polym. J., 23, 1225 (1991).

3. Y. Minoura, K. Shiina, and K. Yoshikawa, J. Polym. Sci., A-1, 5, 2843 (1967).

4. M. Motoi, H. Suda, K. Shimamura, S. Nagahara, M. Takei, and S. Kanoh, Bull. Chem. Soc. Jpn., 61, 1653 (1988).

5. M. Motoi, S. Nagahara, M. Yokoyama, E. Saito, O. Nishimura, S. Kanoh, and H. Suda, Bull. Chem. Soc. Jpn., 62, 1572 (1989).

6. Y. Kawakami, K. Takahashi, and H. Hibino, Macromolecules, 24, 4531 (1991).

7. T. Endo and H. Uno, J. Polym. Sci., Polym. Lett. Ed., 23, 359 (1985).

8. A. Akelah and D. C. Sherrington, Chem. Rev., 81, 557 (1981).

9. E. J. Corey and N. Raju, Tetrahedron Lett., 24, 5571 (1983). 